\title{
Microsurgical and Functional Linguistic Anatomy of Cerebral Basal Ganglia
}

\author{
Serebral Bazal Ganglionların Mikrocerrahi Anatomisi ve Dil Üretimi ile Illişkisi \\ (D) Mustafa Güdük1, (D) Musa Çırak², (D) Baran Bozkurt³, (D) Kaan Yağmurlu3 \\ ${ }^{1}$ Acıbadem Mehmet Ali Aydınlar University, School of Medicine, Department of Neurosurgery, İstanbul, Turkey \\ 2University of Health Sciences Turkey, Bakırköy Dr. Sadi Konuk Training and Research Hospital, Clinic of Neurosurgery, istanbul, Turkey \\ ${ }^{3}$ Virginia University, Department of Neurosurgery, Charlottesville, USA
}

\begin{abstract}
Introduction: The central core of the cerebral hemispheres is located on the medial side of the insular cortex. It is made up of basal ganglia and white matter tracts. The basal ganglia and their white matter connections serve important motor, sensorial, psychological, endocrinological and cognitive functions. Insular gliomas and other deeply located lesions can cause severe morbidity by affecting the basal ganglia and their connections. Hence, a thorough understanding of the anatomy of that area is needed for surgical planning on the insular area. Methods: We dissected and photographed the insular cortex and basal ganglia in five human cadavers via white matter dissection techniques from lateral to medial side.

Results: The structures and connections of the insular cortex and basal ganglia are documented and presented with their functional correlations during the dissections.

Conclusion: Our results will guide the strategy and planning of surgery for the insula and basal ganglia. Additionally, they will be helpful in the follow-up and prediction of morbidities of lesions located in that area.
\end{abstract}

Keywords: Insula, basal ganglion, white matter, grey matter

\section{öz}

Amaç: Serebral hemisferlerin derin santral bölgesi; bazal ganglionlar (subkortikal gri maddeler) ve kompleks ak madde liflerinden oluşur ve insular korteksin hemen mediyalinde yer alır. Bazal ganglionlar sahip olduğu ak madde lif bağlantıları sayesinde motor ve sensöriyal, duygu, endokrin düzenleme, kognisyon gibi fonksiyonlarda önemli rol oynar. Özellikle insular gliomalar ve derin yerleşimli lezyonlara bağlı, bazal ganglionların ve bağlantılarının zarar görmesi ciddi morbiditeye sebep olur. Bu nedenle bu bölgenin mikrocerrahi anatomisinin iyi bilinmesi, insuler bölgeye yapılacak cerrahinin planlanmasında ve cerrahi stratejide çok büyük öneme sahiptir. Yöntemler: Beş adet insan kadavrasında, lateralden mediyale doğru olacak șekilde, insular korteks ve tüm bazal ganglion yapıları ak madde diseksiyon yöntemleri kullanılarak bağlantılarıyla beraber ortaya kondu ve fotoğraflandı.

Bulgular: Insular korteksin uzaklaștııılması sonrası, ak madde bağlantıları, bazal ganglionlar ile bağlantıları ve fonksiyonel korelasyonları tarif edilip, görsel olarak dokümante edildi.

Sonuç: Araştırmamızın sonuçları, santral bölge ve bazal ganglion lezyonlarının, gerek takibinde, gerek cerrahisinde ve morbidite öngörüsünde yardımcı olacaktır.

Anahtar Kelimeler: Insula, bazal ganglion, ak madde, boz madde

\section{Introduction}

The deep central-basal ganglia region of the cerebral hemisphere consists of subcortical areas of gray matter and complex white matter fibers. This region is also called central cor and is localized between the insula cortex in the lateral and the ventricle in the medial (1). Although it is relatively small in size, it has a wide range of sensory, motor, emotional and cognitive functions thanks to its wide afferent connection network. Anatomically, this structure includes the extreme capsule, claustrum, external capsule, lentiform nucleus (putamen + globus pallidus), internal capsule, caudate nucleus and thalamus.

From the perspective of neurosurgery, the surgery of this region is very difficult and the possibility of morbidity is high, due to its location deep in the cerebral hemispheres and the complex network of white matter fibers passing through and around it.

However, as the recent clinical studies and the increase in the number of these studies show; Factors such as the development of new approach 
concepts, studies of white matter anatomy, and the gradual development of diffusion tensor imaging magnetic resonance imaging technique, which enables us to view and evaluate white matter pathways in detail, have increased the possibility of wide resection and survival rates in this region surgery, while also reducing the risk of morbidity (2-10). In this region surgery, the concept of planning and foresight is now established according to the anatomical location of the lesion within the insular cortex and basal ganglia. Various degrees of speech and language disorders are common in central core lesions and surgery. In this study, we aimed to show both the basal ganglia structures from lateral to medial, and the relationship of these structures with all fiber bundles that contribute to language production.

\section{Methods}

Cadaver dissections of this study were performed in the neuroanatomy laboratories of Virginia University (USA). Five postmortem human brain specialties were kept in a $10 \%$ formalin solution for at least 1 month in accordance with the Klingler method, and then arachnoid, pia mater and vascular structures were removed under the operating microscope. Between dissections, specimens were stored in $10 \%$ formalin solution and at $+4{ }^{\circ} \mathrm{C}$. Dissections were performed under Zeiss microscope at $\mathrm{x} 4$ and $\mathrm{x} 40$ magnification, using a microsurgery set (edentulous forceps, Rhoton dissector, metal spatula, microhook) and aspirator.

The cerebral cortex was decorticated with the help of an aspirator and spatula. A lateral to medial dissection was performed on specimens. On the lateral faces of the specimens, short association fibers (U fibers) were removed and long major association fibers were reached. The insula was decorticated and all basal ganglia structures from lateral to medial were exposed.

Each stage was documented by photographing Canon EOS 550 camera with 18-55 and 100 lenses.

Our study does not require patient and Ethics Committee approval, as it is an anatomical laboratory study in a cadaver. The study was conducted in accordance with the principles of the Helsinki Declaration, 2013 (11).

\section{Statistical Analysis}

In our study, the relationship between basal ganglia and white matter was revealed by anatomical dissection techniques, visualized and documented by photographic techniques and then described. In our research, no measurements or comparisons were made that required statistical analysis.

\section{Results}

\section{Insular Cortex and Basal Ganglia Structures}

The surface of the insular cortex faces laterally and is bordered by the anterior, inferior, and superior posterior limitan sulcus. It is divided into two main parts, anterior and posterior, by the central insular sulcus. In the anterior part, which is wide, there are three short gyrus (anterior, middle, posterior) separated by two sulcus, and in the posterior part there are two long gyrus (anterior, posterior) separated by a single sulcus (Figures 1A, B). In the projection of the midpoint of the posterior short gyrus, the genus of the internal capsule and the foramen Monro are located. The central insular sulcus is parallel and aligned with the cerebral central sulcus that separates the frontal and parietal lobes. The insular apex is the highest area laterally above the insular convexity and is located in the lower part of the middle short gyrus. Short insular gyri join at the insular pole; long insular gyri join at the limen insula. The insular pole is located between the anterior limiting sulcus and the central insular sulcus.

Extreme capsule; it arises by decortication of the insular cortex (Figure 1C). It consists of short association fibers that provide the connection between the insular gyri and opercular gyri that extend into the sylvian fissure. It is responsible for the non-articular functions of speech (12).

External capsule; it consists of the ventral external capsule, frontooccipital fascicle (FOF) and uncinate fascicle (UF) fibers. External outer capsule consists of dorsal claustrum fibers distributed in the frontal, parietal and occipital regions (Figure 1D).

Claustrum; it is the structure that emerges when the extreme capsule starts to be taken. Parabolic curve drawn from the middle short insular gyrus towards the midpoint of the posterior long insular gyrus; it divides the claustrum and the external capsule into two: dorsal claustrum and ventral claustrum. Ventral (anteroinferior) klaustrum; it is located within the UF and FOF and consists of gray matter. The dorsal claustrum forms the dorsal external capsule fibers, distributing to the frontal parietal and occipital regions. The claustrocortical system plays a role in the integration of visual, somatosensory and motor information, thanks to its wide distribution from the front of the supplementary motor area to the posterior parietal area (Figure 1E).

Putamen; it occurs after the external capsule is removed (Figure 1E). Together with the caudate nucleus it forms the dorsal striatum. After the putamen is taken medially, the globus pallidus externa is reached (Figure 1F).

Internal capsule; after the medial globus pallidus is removed, all internal capsule fibers are exposed (Figures 1F, G). The anterior branch of the internal capsule is located between the lentiform nucleus (putamen + globus pallidus) and the head of the caudate nucleus. It consists of anterior thalamic peduncle and frontopontin fibers. The internal capsule genus contains connective fibers and superior thalamic fibers that extend between the presentral cortex and the brainstem. Foramen Monro is found in the projection of the genu. The posterior branch of the internal capsule contains corticospinal tract, superior thalamic peduncle (thalamopostcentral part), corticopontine and corticotegmental fibers. The retrolenticular part of the internal capsule contains parietopontine, occipitopontine and posterior thalamic peduncle fiber bundles. Optical radiation fibers are also found within the posterior thalamic fiber bundles.

Caudate nucleus; it is seen with the thalamus after lifting the internal capsule and corona radiata from lateral to medial (Figure 1H). The head of the caudate nucleus is on the lateral wall of the frontal horn, its body is lateral to the body of the lateral ventricle and atrium, its tail is on the roof of the temporal horn. The caudate nucleus is " $\mathrm{C}$ " shaped and the thalamus is located inside the caudate nucleus. 
White Matter Fibers Including in Basal Ganglion Structures or Having Close Anatomical Relationship

Superior longitudinal fascicle (SLF); it is the main association fiber bundle containing high cortical functions in the frontotemporoparietal region. It has been tractographically examined in three sections. SLF-I; lies under the superior frontal gyrus, SLF-II; under the middle frontal gyrus and under the inferior frontal gyrus of SLF-III (Figures 2A, B). Located in the parietal operculum in the suprasylvian area, SLF-III connects the supramarginal gyrus with the pars opercularis. SLF-III is involved in phonological processing (working memory) (9). Stimulation of SLF-III in the dominant hemisphere can cause speech articulation problems such as dysarthria and anarthria. In the non-dominant hemisphere, SLF-III is related to visual-spatial attention, prosody (prosody) and music processing $(13,14)$.

Arcuate fascicle (AF); it connects motor (Broca's area) and sensory (Wernicke's area) language centers. It is divided into two as dorsal and ventral segments (Figure 2A). The ventral segment is ventral to the dorsal segment in the suprasylvian area, but is located anterior to the dorsal segment in the infrasylvian region.

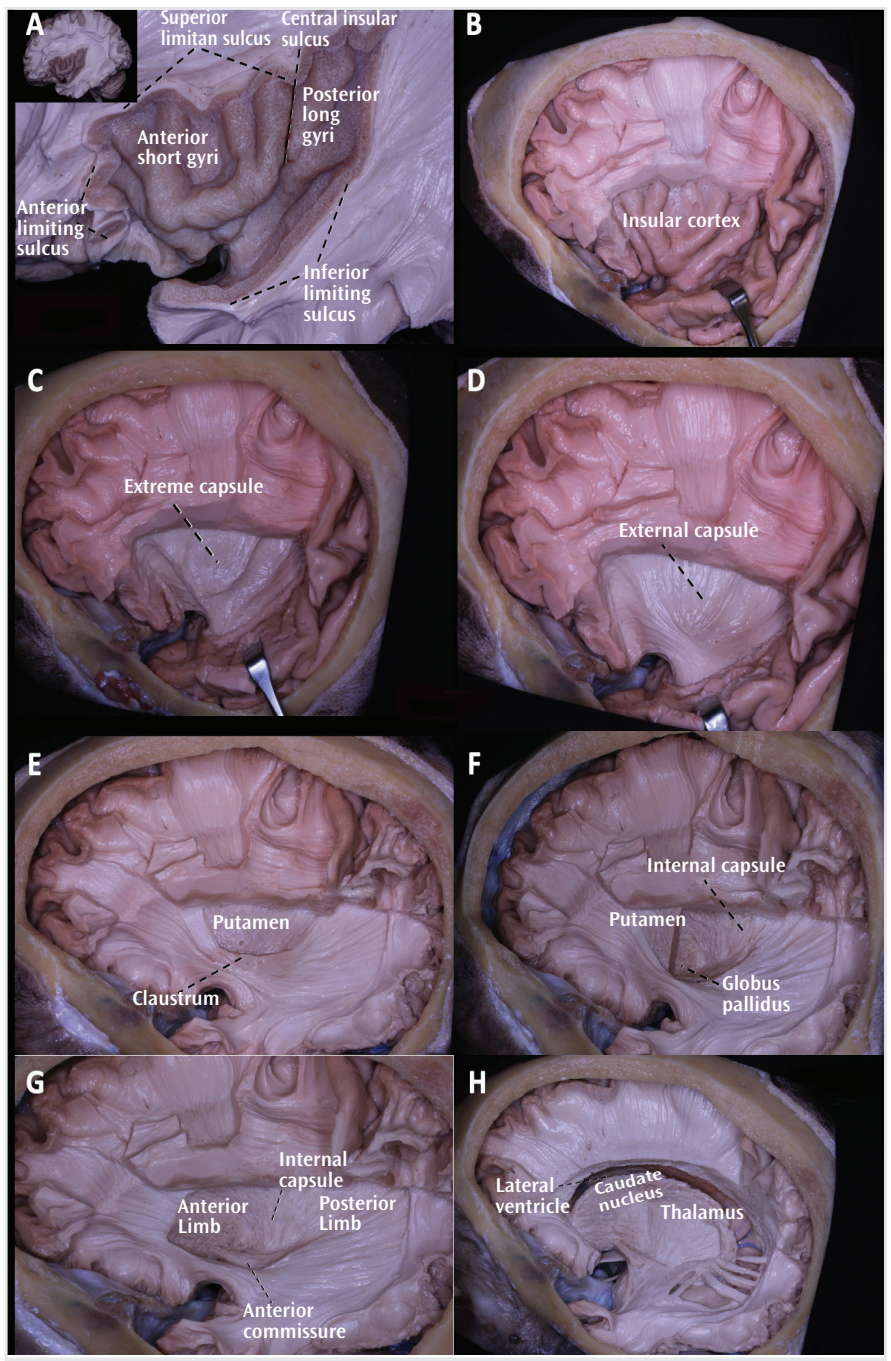

Figure 1. In the left cerebral hemisphere, the appearance of the insular cortex and basal ganglia structures from the lateral
The ventral segment starts from the middle and posterior parts of the superior temporal gyrus and the middle part of the middle temporal gyrus; it passes from the lower part of the supramarginal gyrus and anteriorly medial to the SLF-III in the frontoparietal operculum, and ends in the inferior frontal pars opercularis. The dorsal segment starts from the posterior part of the middle and inferior temporal gyrus and passes through the lower part of the angular gyrus and then runs forward slightly ventrally from the ventral of SLF-II to the middle and inferior frontal gyrus. The ventral segment of the AF is associated with phonological language processing, while the dorsal segment is associated with lexical and semantic language processing. The known classical AF model is equivalent to the ventral segment (15).

Middle longitudinal fascicle; it is located within the superior temporal gyrus. It extends between the Superior temporal gyrus and the inferior parietal lobule (especially the angular gyrus) (Figure 2B). This bundle of fibers, extending from the Inferior parietal lobule (especially the angular gyrus) to the superior temporal gyrus, is thought to play a role in the functions of language in the dominant hemisphere and attention in the non-dominant hemisphere.

Inferior longitudinal fascicle (ILF); it is located in the inferior temporal gyrus by anatomical definition and connects the temporal pole to the dorsolateral occipital cortex (Figure 2B). ILF has been shown to functionally play a secondary role in the inferior fronto-occipital fascicule in the "ventral semantic pathway" associated with the tongue regions in the anterior and middle temporal region.

Inferior fronto-occipital fascicle (IFOF); it connects the frontal and occipital regions. Starting from the prefrontal cortex, it proceeds just above the UF at the level of the limene insula and blends into the extreme and external capsule fibers (Figure 2C) $(9,16)$. It extends posteriorly along the lateral walls of the temporal and occipital horns and ends in the occipital lobe. Together with the FOF and the ILF, it forms the semantic ventral pathway, and as a result of its intraoperative stimulation, semantic (semantic) parafhasia is observed (9).

UF; in the temporal region, it originates from the cortical nucleus of the amygdala and anterior temporal region in front of the temporal horn and moves forward from the inferior of the lentiform nucleus and IFOF at the level of the limen insula to the lateral orbitofrontal area (Figure 2C). It has been reported that the UF is responsible for posttraumatic retrograde amnesia (17). In the subgenual area, the UF, which is thought to be part of the ventral limbic pathway, meets with the fibers of the cingulum, which is considered the dorsal limbic pathway (18). Disconnection can cause behavioral disorder (19).

Frontostriatal tract (FST); it originates from the supplementary motor complex [especially the pre-supplementary motor area (SMA)], turns inferiorly and passes through the medial of the superior limiting sulcus and ends in the caudate nucleus, putamen, and external capsule structures (Figure 2D). The projection is the fiber bundle. With its stimulation in the dominant hemisphere, there is a problem in initiating speech.

Frontal aslant tract (FAT); it originates from the supplementary motor complex, progresses obliquely to the inferior and superficially within 
the inferior frontal gyrus and ends in the pars opercularis (Figure 2D). It takes part in initiating speech and speaking fluently in the dominant hemisphere.

\section{Discussion}

Insular glioma surgery has always been challenging for neurosurgeons due to the complex shape and organization of the insular cortex, the functional importance of the insula, its medial white matter structures and its close relationship with the internal carotid artery, middle cerebral artery, and lenticulostriate vessels. Therefore, until recently, insular gliomas were considered too dangerous for surgical treatment, with an unacceptably high rate of postoperative morbidity. Especially in recent years, in addition to the previous surgical approach-based neuroanatomical studies, the detailed demonstration of the anatomical structures from the insular cortex to the medial with white matter dissection technique and the increase in the studies and documentation on this subject have enabled us to have a better understanding of the central core anatomy $(10,20)$. In addition to this information, molecular

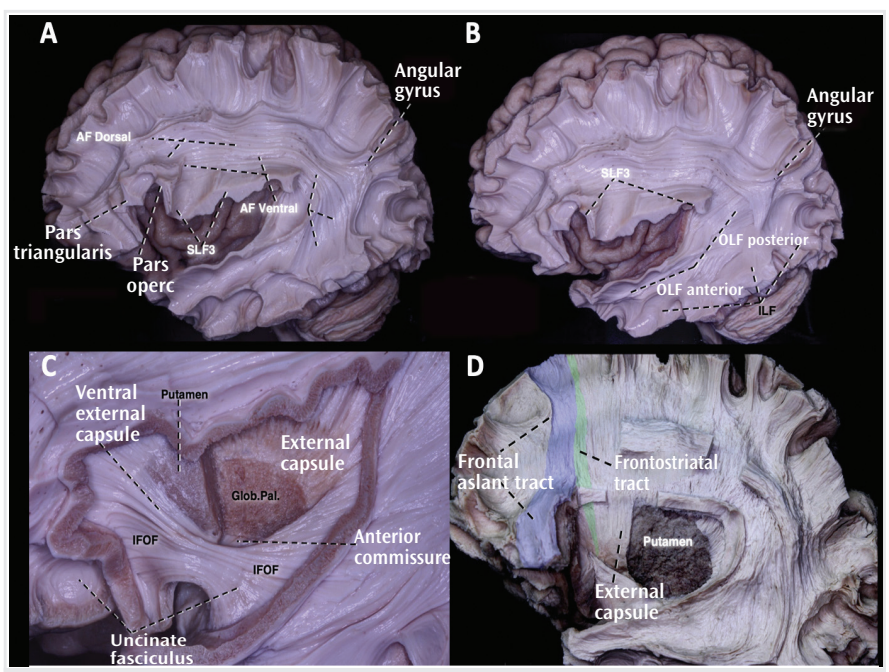

Figure 2. In the left cerebral hemisphere, the appearance of the relationship of basal ganglia and white matter fibers from the lateral

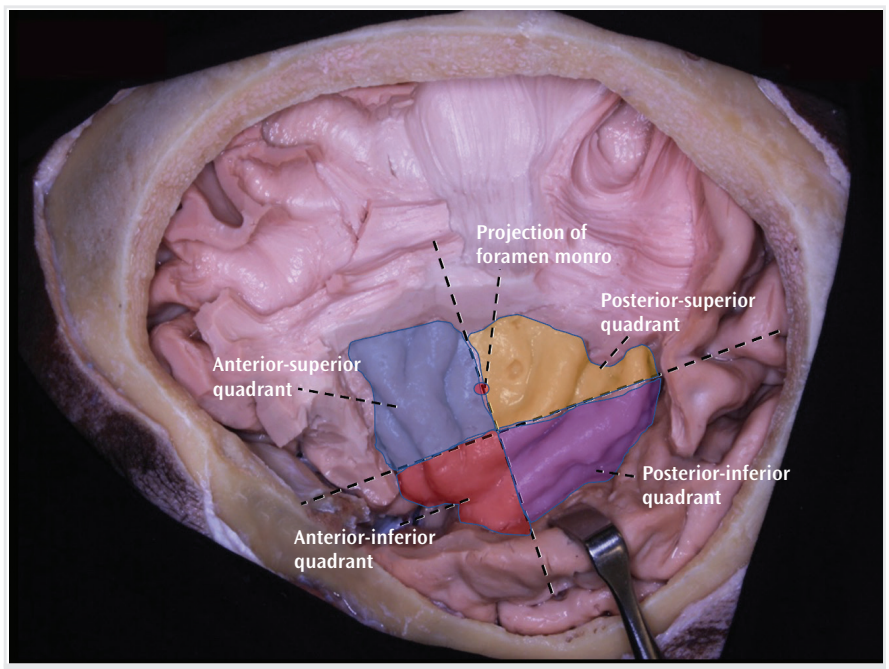

Figure 3. Sanai et al. (8), a lateral view in the left cerebral hemisphere of the separation of insular tumors according to four different quadrants categorization studies of insular glioma that have increased in recent years and the widespread use of awake insular glioma surgery increase the success of total or subtotal excision of the tumor in insular glioma surgery, while decreasing surgical morbidity and increasing the progression-free survival rate for all patients.

In addition to the pathological features of the lesion, the location of the lesion in the central core and its spread to its immediate surroundings are important in order to increase survival, decrease loss of function and predict survival in patients with insular glioma. Very few of insula-derived gliomas are completely located in the insula $(2,3,21,22)$. Also, depending on where the glioma originates in the insula, surgical approach and anatomical considerations may vary. Therefore, it is difficult to establish a common terminology when discussing insular gliomas. Yașargil first classified insular tumors according to their localization, based on his large series. Accordingly, he proposed a classification system based on whether the lesion was included in the insula (type 3), part of the insula (type 3A), or the adjacent operculum (type 3B). In this classification system, insular lesions containing one or both of the paralimbic orbitofrontal and temporopolar areas were classified as type 5A or type 5b, respectively. In addition to this classification, Sanai et al. (8) have created their own classification in order to evaluate proximity to functional areas and predict and plan the possibility of wide resection. According to this classification, the insular cortex is divided into four main regions by a line drawn perpendicular to the sylvian fissure from the foramen Monro (Figure 3). With this classification, they revealed predictions about survival, perioperative morbidity and malign transformation after extensive resection, according to anatomical localization and spread of central Cor-placed tumors. Most insular gliomas are not confined to a single region or only within the central core boundaries. Zone 1 (anterior-superior) predominantly localized tumors are adjacent to the frontal operculum due to their anatomical neighborhood. Zone 2 (posterior-superior) tumors are important anatomical structures in terms of invasion of the presentral gyrus, primary motor cortex and parietal operculum. Zone 3 (posterior-inferior) localized tumors can often invade medial temporal structures, Heschl gyrus is an important cortical neighborhood. Frontobasal and temporal pole invasion can be seen frequently in tumors with zone 4 (anterior-inferior) localization due to their close neighborhood. Anatomical and clinical studies conducted in recent years have shown that damage to subcortical white matter tracts causes more severe clinical deterioration than damage to cortical structures and has a lower chance of recovery (23-26). The central core is sensitive because it contains large projection fiber junctions under the insular cortex and is closely adjacent to important association links in the perisylvian region.

In the medial invasion of central cor anterior-superior tumors, the anterior leg of the internal capsule, putamen and caudate head within the central core may be damaged. Due to the close proximity of the pars opercularis and triangularis in the frontal lobe, various speech disorders can be seen in the tumors of this region due to the damage of Broca and its connections. Also known as motor aphasia, the patient's speech is laborious and often slow, with pauses between words much more frequent than the words themselves. In classical Broca's aphasia, extensive damage involving the Broca area (BA44 and BA45 in the left 
inferior frontal gyrus) and the surrounding frontal areas (BA6, BA8, BA9, BA10, BA46 and BA47) as well as the underlying white matter and adjacent central core structures seen (27). In our dissections, we saw that the FAT fibers started from the SMA and ended in the Broca area. In the dominant hemisphere, due to Broca's damage, there may be a damage at the end of the FAT fibers, and this may cause impairment in speaking initiation and fluency in the tumors of this region. Wernicke aphasia, known as sensory aphasia, usually develops as a result of damage to the posterior region (BA22) of the left auditory asociation cortex (posterior part of the superior temporal gyrus). Often BA37, BA39, BA40 or all three are involved (27). The central core can often be damaged due to its anatomical proximity with posterior-inferior tumors. In conduction (conduction) aphasia, patients can understand simple sentences and make intelligible sentences. However, they cannot repeat sentences word for word, they cannot properly place phonemes. It occurs in subcortical deep-seated lesions in the localisation of the AF connecting the Wernicke and Broca areas. In particular, conduction-type aphasia can be observed due to damage to central Cor tumors located in the anterior superior (zone 1) and posterior superior (zone 2) adjacent to the parietal and frontal operculum, where the AF proceeds under it. SLF-III fibers are the most superficial association fiber bundle within the parietal operculum and runs forward along the parietal operculum. It is closely related to the superior-anterior and superior-posterior quadrants. Anarthria and dysarthria may develop due to the injury of SLF-III fibers in the dominant hemisphere due to invasion of these two region lesions. In the non-dominant hemisphere, prosody (prosody) and music processing may be problematic. Unlike other association fibers involved in language production, the only fiber bundle included in the central core structure is IFOF. The density of the fiber bundle is mostly located in the anterior-superior and posterior-inferior regions within four defined regions, and semantic parafasia may develop in lesions related to these regions or in interventions performed in these regions due to IFOF damage (9). Patients have difficulty naming what they see. UF fibers are also the only projection fiber bundles that are for dilution and whose termination is in putamen, while FST is located in cor and is found in language production. FST fibers originate from the SMA complex like FAT fibers and the two fiber bundles are located very closely inferiorly. While FAT is superficial in the pars opercularis, FST fibers run under the superior limiting sulcus and end in the anterior part of the external capsule, striatum and internal capsule structures. While responsible for voluntary movements in both hemispheres, it plays a role in initiating speech in the dominant hemisphere. Therefore, in the dominant hemisphere, anterior-superior quadrant lesions, when deep central core structures are affected, language production may be impaired in the patient. As in IFOF, FST fibers can also be affected only in lesions located in the central core and not invading the environment.

\section{Conclusion}

In this anatomical study, we have made a detailed description of the insular cortex and central cortical cortical and subcortical structures. We wanted to specifically mention the close relationship with white matter fiber bundles that contribute to language production. We believe that if we have mastered the knowledge of central core and white matter fiber pathways anatomy, we can foresee what kind of language disorder the lesion may cause, according to the anatomical location of the lesion in the central core, we can better plan the surgery and the surgical success will be higher.

\section{Ethics}

Ethics Committee Approval: Our study does not require Ethics Committee approval, as it is an anatomical laboratory study in a cadaver. The study was conducted in accordance with the principles of the Helsinki Declaration, 2013.

Informed Consent: Our study does not require patient, as it is an anatomical laboratory study in a cadaver.

Peer-review: Externally peer-reviewed.

Authorship Contributions: Surgical and Medical Practices - M.G., M.Ç., B.B., K.Y.; Concept - M.G., B.B., K.Y.; Design - M.G., B.B., K.Y.; Data Collection or Processing - M.G., M.Ç., B.B., K.Y.; Analysis or Interpretation - M.G., M.C.., B.B., K.Y.; Literature Search - M.G., M.Ç., B.B., K.Y.; Writing - M.G., M.C.., B.B., K.Y.

Conflict of Interest: No conflict of interest was declared by the authors.

Financial Disclosure: The authors declared that this study received no financial support.

\section{References}

1. Rhoton ALJ. The cerebrum. Neurosurgery 2002; 51(4 Suppl): S1-51.

2. Yașargil MG, Reeves JD. Tumours of the limbic and paralimbic system. Acta Neurochir (Wien) 1992; 116: 147-9.

3. Yașargil MG, von Ammon K, Cavazos E, Doczi T, Reeves JD, Roth P. Tumours of the limbic and paralimbic systems. Acta Neurochir (Wien) 1992; 118: 40-52

4. Türe U, Yașargil DC, Al-Mefty 0, Yașargil MG. Topographic anatomy of the insular region. J Neurosurg 1999; 90: 720-33.

5. Türe U, Yaşargil MG, Al-Mefty 0, Yaşargil DC. Arteries of the insula. J Neurosurg 2000; 92: 676-87.

6. Duffau H, Capelle L, Lopes M, Faillot T, Sichez JP, Fohanno D. The insular lobe: physiopathological and surgical considerations. Neurosurgery 2000; 47: 80110 .

7. Tanriover N, Rhoton ALJ, Kawashima M, Ulm AJ, Yasuda A. Microsurgical anatomy of the insula and the sylvian fissure. J Neurosurg 2004; 100: 891-922.

8. Sanai N, Polley MY, Berger MS. Insular glioma resection: assessment of patient morbidity, survival, and tumor progression. J Neurosurg 2010; 112: 1-9.

9. Yagmurlu K, Vlasak AL, Rhoton AL. Three-dimensional topographic fiber tract anatomy of the cerebrum. Neurosurgery 2015; 11 Suppl 2: 274-305; discussion 305

10. Ribas EC, Yağmurlu K, de Oliveira E, Ribas GC, Rhoton A. Microsurgical anatomy of the central core of the brain. J Neurosurg 2018; 129: 752-69.

11. World Medical Association. World Medical Association Declaration of Helsinki: ethical principles for medical research involving human subjects. JAMA 2013; 310: 2191-4.

12. Makris N, Pandya DN. The extreme capsule in humans and rethinking of the language circuitry. Brain Struct Funct 2009; 213: 343-58.

13. Schiff HB, Alexander MP, Naeser MA, Galaburda AM. Aphemia. Clinicalanatomic correlations. Arch Neurol 1983; 40: 720-7.

14. Loui P, Alsop D, Schlaug G. Tone deafness: a new disconnection syndrome? J Neurosci 2009; 29: 10215-20. 
15. Glasser MF, Rilling JK. DTI Tractography of the Human Brain's Language Pathways. Cereb Cortex 2008; 18: 2471-82.

16. Peltier J, Verclytte S, Delmaire C, Pruvo JP, Godefroy O, Le Gars D. Microsurgical anatomy of the temporal stem: clinical relevance and correlations with diffusion tensor imaging fiber tracking. J Neurosurg 2010; 112: 1033-8.

17. Levine B, Black SE, Cabeza R, Sinden M, Mcintosh AR, Toth JP, et al. Episodic memory and the self in a case of isolated retrograde amnesia. Brain 1998; 121: 1951-73.

18. Fernández-Miranda JC, Rhoton ALJ, Alvarez-Linera J, Kakizawa Y, Choi C, de Oliveira EP. Three-dimensional microsurgical and tractographic anatomy of the white matter of the human brain. Neurosurgery 2008; 62(6 Suppl 3): 989-1026.

19. Heimer L, Van Hoesen GW, Trimble M, Zahm DS. The anatomy of the basal forebrain. Heimer L, Van Hoesen GW, Trimble M, Zahm DS, editors. Anatomy of Neuropsychiatry: The New Anatomy of the Basal Forebrain and Its Implications for Neuropsychiatric Illness. San Diego: Academic Press; 2008.p.27-67.

20. Ribas EC, Yagmurlu K, Wen HT, Rhoton ALJ. Microsurgical anatomy of the inferior limiting insular sulcus and the temporal stem. J Neurosurg 2015; 122 : 1263-73.
21. Yaşargil MG. Microneurosurgery IV B: Microneurosurgery of CNS Tumors. Yaşargil MG, editor. Stuttgart, New York: Georg Thieme Verlag; 1995.

22. Hervey-Jumper SL, Li J, Osorio JA, Lau D, Molinaro AM, Benet A, et al. Surgical assessment of the insula. Part 2: validation of the Berger-Sanai zone classification system for predicting extent of glioma resection. J Neurosurg 2016; 124: 482-8.

23. Burger PC, Heinz ER, Shibata T, Kleihues P. Topographic anatomy and CT correlations in the untreated glioblastoma multiforme. J Neurosurg 1988; 68 : 698-704.

24. Türe U, Yașargil MG, Friedman AH, Al-Mefty 0. Fiber dissection technique: lateral aspect of the brain. Neurosurgery 2000; 47: 417-26.

25. Yașargil MG, Türe U, Yaşargil DCH. Impact of temporal lobe surgery. J Neurosurg 2004; 101: 725-38.

26. Duffau $\mathrm{H}$. New concepts in surgery of WHO grade II gliomas: functional brain mapping, connectionism and plasticity--a review. J Neurooncol 2006; 79: 77115.

27. Boller F, Grafman J, editors. Handbook of Neuropsycology, Vol. 1. Amsterdam: Elsevier Inc; 1987.p.3-46. 